\title{
Condiciones y ambiente laboral de trabajadoras y trabajadores del retail de La Araucanía, Chile*
}

\author{
Working conditions and work environment of workers in retail businesses of \\ La Araucanía, Chile
}

\author{
Hernán Riquelme Brevis* \\ Sandra López Dietz ${ }^{* * *}$ \\ Matías Riquelme Brevis ${ }^{* * *}$ \\ Natalia Meza Serra ${ }^{* * * *}$
}

\begin{abstract}
Resumen: En el presente trabajo se desarrolla un análisis de las condiciones de trabajo y el ambiente laboral/post laboral de trabajadoras y trabajadores de tiendas comerciales de La Araucanía. El foco de estudio se centró en determinar las desigualdades de género en estas dos dimensiones del retail como sector económico, que cada vez adquiere mayor protagonismo en la sociedad chilena. A partir de una metodología cuantitativa, se estableció contacto con trabajadoras y trabajadores de cinco empresas del retail de la región $(n=205)$, quienes respondieron una encuesta conformada por seis secciones. Dentro de los principales resultados- los cuales fueron analizados como variables particularescabe destacar una alta precarización respecto a las condiciones laborales; diferencias de género en torno a las prestaciones de salud; doble jornada feminizada; insatisfacción relativa a las labores rutinarias en la empresa, y brechas salariales de género.
\end{abstract}

Palabras clave: Retail, Género, Trabajo precario, Desigualdad social.

\begin{abstract}
In this paper, an analysis of the working conditions and the working/post-work environment of workers in commercial shops in La Araucanía is developed. The focus of this study was identifying gender inequalities in these two dimensions of retail that is increasingly taking center as
\end{abstract}

\footnotetext{
* Este artículo está adscrito a los proyectos FONDECYT 1180892 y DIUFRO DI18-0047. Los autores agradecen los relevantes comentarios de los evaluadores anónimos que permitieron enriquecer el artículo.

${ }^{* *}$ Chileno. Coautor. Doctor en Ciencias Sociales. Investigador y docente en la Universidad Autónoma de Chile y la Universidad Arturo Prat. h.riquelmebrevis@gmail.com

${ }_{* * *}$ Chilena. Coautora. Doctora en Procesos Sociales y Políticos en América Latina. Investigadora y docente en la Universidad de la Frontera (UFRO). Co-Directora del Observatorio de Medios y Movimientos Sociales (OMMS) sandraldietz@gmail.com

**** Chileno. Coautor. Cientista Político. Magíster en Gestión Pública Municipal y Desarrollo Local. Estudiante del programa de Doctorado en Ciencias Sociales (UFRO). Docente en la Universidad Mayor, Sede Temuco, Chile. Co-investigador en el OMMS-UFRO. matiasriquelmeb@gmail.com

${ }^{* * * * *}$ Chilena. Coautora. Periodista. Licenciada en Comunicación Social. Asistente de investigación en el OMMSUFRO. mezaserranatalia@gmail.com
} 
economic sector in Chilean society. On the basis of a quantitative methodology, workers from five retail companies in the region were contacted $(n=205)$, who answered a survey consisting of six sections. Among the main results -which were analyzed as particular variables- it is relevant to mention that there was a high level of precariousness regarding to working conditions; gender differences in health services; double feminized working hours; dissatisfaction related to routinely work in the company and gender wage gaps.

Keywords: Retail businesses, Gender, Precarious job, Social inequity.

Recibido: 18 junio 2019 Aceptado: 9 octubre 2019

\section{Introducción}

El sector económico del retail se instala de manera decisiva en el escenario social chileno durante la última década, traspasando lo netamente ligado al ámbito comercial. Dentro de las transformaciones socioeconómicas y culturales que se identifican al momento de referirse al retail y su fuerza de trabajo, emergen categorías sustanciales que han sido investigadas en el ámbito local. Destaca la matriz precaria de sus trabajadores (Ramos, 2009); la heterogeneidad de los perfiles identitarios (Stecher, 2012); la influencia de la publicidad en el consumo (Porth, Vegara, Gómez y Labarca, 2017), y las paupérrimas condiciones de salud a las que se ven enfrentados (Hernández, Almendras, Illánes y Miranda, 2018). Este escenario se torna sumamente revelador de la tendencia a generar puestos de empleo que proyectan incertidumbre y desamparo respecto al devenir de una parte importante de la población laboralmente activa, develando el corpus constitutivo del neoliberalismo chileno.

Esta investigación se desarrolla en el contexto de la adjudicación de un Proyecto de Extensión Académica ${ }^{1}$ de la Universidad de La Frontera presentado por el equipo del Observatorio de Medios y Movimientos Sociales (OMMS) de la Facultad de Educación, Ciencias Sociales y Humanidades. El proyecto tuvo dos objetivos principales, el primero, conocer la percepción de los trabajadores del retail en torno a diversas dimensiones de la vida cotidiana y el ámbito laboral; y el segundo, identificar diferencias de género existentes en diversas dimensiones de la vida cotidiana y el ámbito laboral. El estudio de carácter exploratorio se abordó desde una metodología participativa donde a partir de reuniones periódicas y jornadas de discusión y reflexión con las y los dirigentes de la Federación de Sindicatos del Retail (FESIR) de Temuco, desarrolladas durante el año 2016 y 2017, se fue definiendo en conjunto con el OMMS las problemáticas a abordar, las dimensiones de la encuesta y las variables que ésta contendría. Finalmente se decidió conjuntamente cuáles serían los establecimientos en los que se aplicaría la encuesta, realizando la toma de datos en los siguientes establecimientos: París Portal, Supermercado Unimarc Pinto 72, Supermercados Cugat, Easy y Supermercado Líder Prieto Norte, todos ubicados en la

\footnotetext{
1 Proyecto Nro. EXT17-0044 Financiado por la Dirección de Extensión de la UFRO.
} 
ciudad de Temuco. El criterio para definir estos establecimientos fue deliberado en conjunto con las y los dirigentes sindicales, tomando en consideración el número de trabajadores y la viabilidad de aplicar las encuestas en base al universo total de trabajadores por establecimiento.

El estudio de las condiciones laborales de los trabajadores del retail se vuelve un espacio de investigación idóneo para explicar las luces y sombras de la sociedad chilena. Es en el retail donde confluyen diversas experiencias y realidades que encarnan múltiples formas de precariedad, no solo supeditada al ámbito económico, más bien como una condición que tiende a vincularse con los aspectos psicológicos y culturales que conllevan a plantearse el papel de la incertidumbre, la inseguridad y el desamparo en sociedades capitalistas periféricas (Julián, 2017).

A partir de la representación del retail se puede caracterizar el modo de vida actual de los trabajadores, lo cual involucra analizar aspectos vinculados a la vida cotidiana de estos, más allá del horario laboral. Emerge la categoría género, y su poder explicativo, para dar cuenta de las desigualdades que se reproducen tanto en el espacio laboral como en el espacio doméstico, provocando la reproducción de roles diferenciados respecto al hombre y la mujer en la sociedad. Cabe precisar que en este estudio definimos la compleja relación entre sexo y género a partir de la definición de Guerra (2016), en tanto: "el ser humano concreto sólo puede ser reconocido como un sujeto con diferenciación sexual y diferenciación de género simultáneas. Este binomio, en el plano de lo real se encuentra en una «relación insuprimible». La identidad sexual se encuentra "participada» en la identidad de género y la identidad de género incide de modo real en la identidad narrativa del yo." (p. 162); y, a su vez, consideramos que existe una articulación específica entre sexo-género y clase social, tal como lo aborda Kergoat (2003) cuando señala que:

La división sexual del trabajo se caracteriza, por un lado, por la asignación prioritaria de los hombres a la esfera productiva, y de las mujeres a la esfera reproductiva; y, por el otro, por el acaparamiento por parte de los hombres de las funciones con un alto valor social agregado [...] Esta forma de división social se halla regida por dos principios organizadores: el principio de separación (hay trabajos de hombres y trabajos de mujeres) y el principio jerárquico (un trabajo de hombre "vale" más que uno de mujer). ( p. 847).

Enfatizamos en la categoría género por sobre la variable sexo, esta elección se justifica en la relevancia que adquiere el género como enfoque para comprender las desigualdades sociales, particularmente en el sector del retail. En términos concretos, la aplicación del instrumento enfatizó en dimensiones del género en el ámbito del trabajo y sus derivaciones, las cuales permitieron desarrollar el análisis que se presentará en las próximas páginas.

La presente investigación analiza las condiciones laborales de las y los trabajadores del retail de La Araucanía, Chile, vinculando los espacios productivos y reproductivos en el desarrollo de sus rutinas cotidianas. Para esto, fue de suma utilidad incorporar el enfoque de género ya que es en este ámbito donde se puede reconocer y analizar las diferencias sociales a las que se ven enfrentadas las trabajadoras del retail en comparación a los hombres que se dedican a las mismas actividades productivas. 
Se utilizó el enfoque cuantitativo para levantar información a través de la aplicación de un cuestionario a trabajadores del retail de la región, analizando seis dimensiones, no obstante, para los objetivos del presente trabajo se presentarán resultados de $\operatorname{dos}^{2}$, a saber: Condiciones laborales y Percepción del ambiente (post)laboral. Respecto al ambiente laboral, cabe señalar que nos remitiremos a factores psicosociales y del entorno que influyen en las y los trabajadores (Contreras, Reynaldos y Cardonas, 2015), mientras que por condiciones laborales consideramos aquellos factores que emergen para precarizar las relaciones laborales y fomentar el crecimiento del sector servicios de la economía (Barattini, 2009).

El artículo engloba cinco secciones, además de la introducción. En la primera se contextualiza el papel de retail en Chile, vinculando aspectos de la empleabilidad, productividad y perfil laboral. En la segunda sección se desarrolla una discusión conceptual en torno al género y el trabajo como categorías sustanciales de la teoría social contemporánea. En la tercera parte del artículo se describen aspectos sociodemográficos de La Araucanía, como una región con altos indicadores de desigualdad, exclusión sociocultural y pobreza. En la cuarta sección se exhiben los principales resultados del estudio, dejando entrever asimetrías socioeconómicas entre hombres trabajadores y mujeres trabajadoras del retail. Finalmente, se desarrolla una discusión respecto a la situación social y económica del retail de La Araucanía desde una perspectiva de género, esbozando posibles líneas de acción y reflexión.

\section{Contexto del retail en Chile}

El modelo económico neoliberal ha penetrado con severidad la estructura económica nacional desde la segunda parte del siglo XX. A modo de antecedente clave, en Norteamérica encontramos que el retail constituye la industria más grande y de salarios más bajos, donde jóvenes y mujeres se emplean a tiempo parcial por horas o fines de semana con el objetivo de mejorar su calidad de vida (Carré y Tilly, 2009, 2017). Al respecto, Ikeler (2018), realiza un análisis comparado entre los procesos de la industria del retail y el servicio público en Estados Unidos. Para el autor, el retail es un espacio económico altamente precarizado y sin una tradición sindicalista potente. Empresas como Woolworth's, y J.C. Penney se caracterizan por otorgar bajos sueldos a sus trabajadores (en su mayoría mujeres).

Esta realidad no es exclusiva del norte del contiente, más bien se torna un suceso que diversos países han asumido de manera natural y espontánea, casi como un elemento constitutivo de la existencia humana. Una forma de comprender las causas de este fenómeno está dada por la matriz cultural del neoliberalismo, encarnado en lo que Moulian (1998) denomina la desvalorización del trabajo y una hiper valorización del consumo. Esta problemática conlleva a la generación de diversas frustraciones en el trabajador, que se ve restringido en su organización política y altamente enajenado. Emerge y se torna un ícono de la cultura capitalista el mall, como espacio idóneo del consumismo, donde los sectores pobres pueden soñar con invertir sus posiciones de clase por un momento de sus vidas a través del consumo.

2 Las dimensiones restantes responden a otros trabajos desarrollados por el equipo de investigación. 
Para los objetivos del presente estudio, se vuelve menester comprender lo relativo al retail como una actividad que trasciende lo netamente comercial, por tanto, cabe precisar la definición de la industrial de retail. Una mirada clarificadora es aquella que plantea Calderón (2006), quien lo define de la siguiente manera:

El uso de nuevos sistemas y principios de gestión (lean- retailing), de nuevas tecnologías de scanning y de fuertes procesos de profesionalización, estandarización y racionalización de la gestión permiten un incremento de la productividad y reducción de costos en toda la cadena productiva del negocio (Stecher, Martinic, 2018, p. 3)

En este contexto se logran establecer criterios mediante los cuales el trabajador asociado a la industria del retail genera dinámicas cotidianas que fundan la representación cultural del sujeto, entendiendo "lo cultural" a partir de Kotler (2006), quien propone:

La cultura es el determinante fundamental de los deseos y del comportamiento de las personas. Esta está conformada por subculturas que proveen a sus miembros de factores de identificación y socialización más específicos (...). A su vez, las subculturas se componen de clases sociales: divisiones homogéneas, permanentes, ordenadas jerárquicamente, en las que se comparten valores, intereses y comportamientos similares; determinadas por su profesión, el nivel de ingresos, de bienestar, la educación y los valores. (Kotler, 2006, p. 14).

La creación y sustento empírico del retail se asocia a la globalización y el desarrollo tecnológico, donde impera la cultura del consumo (Moulian 2002, 1997) y la tecnificación de la industria productiva, particularmente asociada al comercio y el espacio urbano, ampliándose en las últimas dos décadas y convirtiéndose en uno de los sectores más importantes del país en términos de crecimiento económico (más de 2.000 locales comerciales); lo cual lo transforma en un relevante polo de empleo (sobre 260.000 empleos directos); factor clave en el crecimiento del Producto Interno Bruto que impacta en "la innovación tecnológica y utilización de diversas estrategias de flexibilidad organizacional externa (en las formas de empleo y en la organización productiva) e interna (temporal, salarial y en la organización del proceso de trabajo" (Stecher, 2012, p. 12).

Hacia fines de la década de los ochenta, en pleno auge del neoliberalismo, se presentó un aumento del ingreso per-cápita en Chile, lo que trajo aparejado un fuerte aumento de los centros comerciales, posibilitando la intromisión de nuevos agentes al mercado del retail. De esta manera, en el año 1990 se inaugura Plaza Vespucio, el primer centro comercial dirigido, principalmente, a los sectores medios de la población. Por otra parte, “en 1990 nace Mall Alto Las Condes, el más lujoso centro comercial de Chile en la época, orientado principalmente a las clases más altas" (Rodríguez, 2003, p. 9).

A nivel latinoamericano, se viven procesos de inserción del mundo del retail desde diversas perspectivas que permiten comprender el corpus primigenio de la economía neoliberal. Tal es el caso argentino, donde la tercerización y precarización juegan un rol central al momento de enfatizar en el desarrollo del trabajo, principalmente asociado a los supermercados, industria clave para el retail. Al respecto, Fernández y Longo (2018) 
sostienen: "desde su consolidación en nuestro país en la década del '90 las cadenas de grandes supermercados se convirtieron en uno de los ejemplos paradigmáticos de la precarización del trabajo. En la última década, junto con el crecimiento económico, mejoraron las condiciones laborales y aumentó la presencia sindical en los espacios de trabajo, pero sin embargo la tercerización se consolidó e incluso se expandió como una característica propia del sector" (p. 222).

A su vez, podemos apreciar una situación similar en el proceso mexicano de expansión de la industria: "en el decenio de los noventa la ciudad de México siguió perdiendo su carácter de motor industrial de la nación; la ciudad capital continuó especializándose en esos años en las actividades de comercio y servicios, y sus micronegocios siguieron expandiéndose" (García, 2009, p. 9). Entendemos en estos ejemplos que los procesos económicos asociados al retail en Latinoamérica surgen de la necesidad por crear nuevas fuentes de trabajo en contextos de crisis económicas, pero no cualquier tipología de trabajo, un trabajo precario con sueldos reducidos donde la conciencia, organización y desarrollo del propio trabajador se ven limitados a procesos de funcionalidad en su contexto laboral.

En el escenario latinoamericano existen distintos estudios que señalan la importancia de los nuevos procesos de inserción tecnológica en el mundo del trabajo, particularmente en la industria del retail, como señala el informe de CEPAL sobre asuntos de género y el mundo del trabajo (2019):

Existe consenso en que las nuevas tecnologías desplazarán muchos trabajos rutinarios de baja calificación y se requerirán recursos humanos con nuevas y diferentes habilidades para manejarlos y administrarlos. Esto abre no solo la oportunidad de impulsar la productividad, pero también del surgimiento de empleos nuevos que se caractericen por tener mayor calificación y basarse en tareas menos rutinarias y repetitivas. El desafío para la región es aprovechar estas oportunidades para mejorar la calidad de los empleos en los que se insertan las mujeres" (Vaca, 2019, p.37).

Por tanto, es de vital relevancia realizar análisis a nivel territorial respecto a la interpretación y niveles de conciencia de los trabajadores en relación con los diversos procesos y transformaciones en el mundo del trabajo y las relaciones de género.

En otro orden de ideas, las empresas ligadas al mundo del retail tienen más bien un carácter heterogéneo en su composición sociodemográfica (jóvenes, adultos y adultos mayores; varones y mujeres; sujetos con y sin experiencia laboral; nivel de estudio que va desde la educación escolar incompleta, la educación técnica y educación superior terminada/incompleta). En términos específicos, "dentro de dicha heterogeneidad, predominan las mujeres (60 a $80 \%$ en las tiendas), los jóvenes (60\% menor a 35 años), los trabajadores de baja calificación (aproximadamente $80 \%$ con educación media), sin mayor experiencia laboral previa y pertenecientes a sectores urbano-populares" (Stecher, 2012, p. 12).

En efecto, se trata de una fuerza de trabajo de baja empleabilidad, sin mayores requisitos en cuanto a su cualificación, ampliamente disponible en el mercado laboral y de 
bajo costo para las empresas, por lo cual, se transforma en una de las pocas formas de encontrar un empleo formal para aquellos que están en condiciones precarias de existencia.

Finalmente, cabe destacar el modelo productivo de las tiendas del retail, el cual "se basa en un conjunto de innovaciones flexibles o post-fordistas que coexisten con ciertos principios de racionalización taylorista del trabajo" (Stecher, Godoy \& Toro, 2010, p. 12). Por lo mencionado, la existencia de la división espacial dentro de las tiendas (secciones o departamentos claramente delimitados y con funciones específicas) conlleva, por ejemplo, a que en un supermercado figuren cajas, verdulería, carnicería, panadería, cosméticos, entre otros departamentos, lo que influye en la diferenciación jerárquica dentro del mundo del trabajo y las dinámicas laborales que se establecen en el espacio laboral. Esto trae como consecuencia, por un lado, prototipos ligados a factores como autonomía y salario de los operarios y vendedores, por otro lado, la estandarización y protocolización del proceso de trabajo en torno a tareas sencillas de ejecución, lo que según Stecher (2010) incluye intercambios de comunicación estandarizados entre vendedores y clientes; una poderosa jerarquía a nivel de ventas; mecanismos de control exacerbados, y desgaste físico y emocional del trabajador.

\section{Género y Trabajo: entre el mercado laboral y el hogar}

Como señalamos en la introducción, nos interesa abordar el análisis de los resultados de la aplicación de los cuestionarios a trabajadores y trabajadoras del retail desde un enfoque de género que permita dar cuenta de las distintas formas de inserción laboral y vivencia de las desigualdades de género objetivas y percibidas por las personas encuestadas. En este marco nos parece central la definición de Rubin (1986) en torno a la noción de sistema sexo- género, entendido como "el conjunto de disposiciones por el que una sociedad transforma la sexualidad biológica en productos de la actividad humana, y en el cual se satisfacen esas necesidades humanas transformadas" (Rubin, 1986, p 7).

Así, para Rubin (1986) este sistema sexo-género atribuye ciertas características, aptitudes y actitudes a cada uno de los dos sexos, de tal forma que se naturalizan como atributos propios y esenciales de lo femenino o masculino en una sociedad concreta y en determinado momento histórico. En este sentido, Facio y Fries (2005), señalan que la noción de género alude "tanto al conjunto de características y comportamientos, como a los roles, funciones y valoraciones impuestas dicotómicamente a cada sexo a través de procesos de socialización, mantenidos y reforzados por la ideología e instituciones patriarcales" . (p. 271).

Como consecuencia, podemos observar en la investigación empírica que en el mundo del trabajo es posible identificar esta asignación de roles y funciones según los atributos asumidos como inherentes a cada sexo, y cómo, además, esa asignación trae aparejada una valoración diferente para el trabajo desarrollado por hombres y mujeres, valoración que, como veremos en el apartado de los resultados, es percibida como desigual por las mujeres trabajadoras del retail. Valdés (2012), sostiene que género designa lo socialmente entendido como masculino y femenino, lo cual produce diferencia sexual entre hombres y mujeres en momentos históricos determinados, articulando atributos que generan desigualdades sociales y capacidades propias de hombres y mujeres, sobre todo desde una perspectiva socio-política que entrega a las mujeres una inferiordad biológica 
como muestra de desventaja social. En este sentido, encontramos en la familia, como institución donde se reproducen patrones sexuados, el espacio tradicional histórico donde se han asignado a las mujeres roles asociados a la reproducción biológica y doméstica (Rebolledo y Valdés, 2018).

Como contraparte de la comprensión tradicional de la familia como espacio propio de las actividades de las mujeres, surgen teorías feministas que revisan el trabajo de Marx en post de la emancipación de la mujer. Federici (2013), argumenta que se abre una relevante crítica a partir de la importancia del trabajo reproductivo, planteando romper con las diferencias entre trabajo asalariado y no asalariado desde el reordenamiento de las relaciones sociales imperantes y la reivindicación del interés colectivo.

Asimismo, tal como han planteado diversas teóricas, las relaciones de género están "cruzadas" por las relaciones de poder existentes en las esferas macro y micro sociales. Scott, ha conceptualizado esta relación entre género y poder señalando que "el género es un elemento constitutivo de las relaciones sociales basadas en las diferencias que distinguen los sexos, y el género es una cadena primaria de relaciones significantes de poder" (1985, p.23). Nos resulta reveladora la definición realizada por Scott respecto al aspecto significante de las relaciones de género, en tanto estas relaciones están sustentadas en una ideología (patriarcal) que es vivida como una subjetividad específica en las y los trabajadores en el contexto del modelo neoliberal y las condiciones de precariedad del trabajo actual, cada vez más flexibilizado (Antunes, 2005; Lojkine, 1995).

Cabe precisar que cuando hablamos de ideología patriarcal tomamos la definición acuñada por Facio y Frias (2005), respecto a que esta ideología construye las diferencias entre hombres y mujeres de tal forma que la "inferioridad" de la mujer es considerada como biológicamente inherente o natural (2005, p. 261), ideología que, si bien sostiene el "privilegio masculino", también se convierte en una limitante para los propios hombres al asignar atributos naturales e inherentes también para ellos.

Ahora bien, si avanzamos en articular el enfoque de género con un análisis de clase, partimos por concebir la noción de explotación como aquella relación entre las clases que hace referencia a la apropiación del producto del trabajo excedente que produce la clase trabajadora por parte de la clase poseedora de los medios de producción. (D' Atri, 2004). En ese marco, el marxismo clásico dio cuenta de la existencia de una división sexual del trabajo entre hombres y mujeres. En este sentido, "la primera división del trabajo es la que se hizo entre el hombre y la mujer para la procreación de hijo" (Marx y Engels, citado por Engels, 1848 (1966) p. 27). Más aún, el mismo Engels señala que la familia monógama se constituye a partir de la emergencia de la propiedad privada, de tal forma que este nuevo modelo de relación entre hombres y mujeres se compone en una relación de opresión en la cual el hombre representa al burgués, mientras que la mujer representa al proletario. Para ambos autores en la familia monógama se puede observar el primer antagonismo de clase (Engels, 1848 (1966) p. 32).

Esta situación, analizada por el marxismo clásico que sitúa a la mujer en un lugar subordinado en la familia, se complejiza al incorporarse al mercado laboral, especialmente con el desarrollo del capitalismo, donde en su doble rol de mujer trabajadora y responsable de las tareas domésticas, ella pasa a desarrollar una doble jornada laboral, articulándose por tanto una relación de explotación/opresión. En este sentido, varios trabajos han señalado la articulación entre patriarcado y capitalismo, tal como señala Toledo (2001): 
La venta de la fuerza de trabajo del proletario/a está garantizada por las actividades domésticas realizadas, la gran mayoría de las veces, por la mujer, sea ella trabajadora productiva o no (...) Se entiende entonces que esa garantía para el capital sea una de las principales razones para que el capitalismo mantenga viva la forma de unión de la familia patriarcal, como parte de sus intereses. El casamiento, con su "contrato de dependencia" de la mujer hacia el hombre, facilita el control del capitalismo en relación a la participación femenina en el mundo del trabajo productivo, reafirmando la importancia de las actividades domésticas y maternales (Toledo, 2001, p. 44).

Mazzei (s/f), afirma, en el mismo sentido, que la preservación de la familia patriarcal en el marco del modo de producción capitalista se debe a la relación división socio-sexual desigual del trabajo, perpetuando así la condición de explotación/opresión de las mujeres trabajadoras. Es decir, el capital no solo extrae plusvalía de la trabajadora de manera directa, sino que además lo hace de manera indirecta a partir de apropiarse de su trabajo doméstico no remunerado que permite la reproducción social de la mano de obra.

En una línea similar, Sato (2018), en un trabajo en torno a las mujeres trabajadoras del retail en Chile, acuña la noción de "patriarcado capitalista" para dar cuenta de la relación y articulación de ambos sistemas, cuyas implicancias para las mujeres trabajadoras produce un sistema donde se conjugan la explotación en el hogar, la explotación en el trabajo remunerado, la dominación masculina en el hogar y la dominación masculina en el trabajo remunerado. Como consecuencia, la autora señala que los roles de género establecidos en el sistema patriarcal instauran una división del trabajo para cada sexo (contrato de género), y además una jerarquías y valores diferenciados para las tareas definidas como "femeninas y masculinas", de tal forma que las atribuidas a las mujeres tienen una valoración menor que las atribuidas a los varones. A partir de esta base Sato analiza cómo en el retail se reproducen las relaciones de género, concluyendo que "El mercado utiliza estas categorías para desvalorizar el trabajo de las mujeres" (Sato, 2018, s/n).

En el mismo sentido, Yañez (2004), sostiene que a los cambios en las relaciones de género a partir de los avances de los tipos de trabajo flexibles en Chile han trastocado lo que la autora denomina la "relación laboral normal" masculina y el contrato de género, según el cual el hombre participa del mercado laboral y del espacio público (el "hombre proveedor" cuyo salario permite la subsistencia de la familia), mientras que la mujer se dedica al cuidado de la familia y las tareas domésticas ("mujer cuidadora"). A partir de estas categorías analíticas Yañez señala:

La figura de la relación laboral normal como trabajo de tiempo completo y con continuidad hace que las mujeres, al entrar al sistema laboral, enfrenten una estructura orientada a normalidades masculinas que dificulta compatibilizar el trabajo remunerado con el trabajo de cuidado, la vida personal y comunitaria (2004, p. 54).

El trabajo reciente de Hatton (2017), analiza con precisión la categoría "trabajo invisible" para dar cuenta específicamente de los mecanismos por medio de los cuales se 
produce esta desvalorización del trabajo, especialmente el femenino en su doble jornada laboral, la "visible" (la jornada laboral en el trabajo remunerado fuera del hogar) y la "invisible" (el trabajo no remunerado de cuidado de hijos e hijas y tareas domésticas en el hogar). Para Hatton, estos mecanismos son centralmente socioculturales, e incluyen "al menos dos niveles: (1) en los cuerpos de los trabajadores a través del requisito de trabajo corporal oculto; y (2) sobre las habilidades de los trabajadores naturalizándolos y devaluándolos" (Hatton, 2017, p. 340), en el caso particular de las mujeres trabajadoras, estos mecanismos socioculturales tienen para el autor una base ideológica basada en creencias hegemónicas de género, entre otras.

La relación entre género y precariedad está atravesada por los roles que el capitalismo asignó a hombres y mujeres. Mientras al hombre lo situó como fuerza de trabajo, a la mujer la relegó a la reproducción y a la dependencia económica, división que constituye desigualdades de género, donde las mujeres están más propensas a situaciones de precariedad (Lázaro y Jubany, 2017). Dentro del precariado, las personas con empleos por horas o temporales son el grupo central (Standing, 2013), en este sector las mujeres ocupan un papel protagónico (Ikeler, 2018), principalmente por una condición sociocultural asignada que la relega a la esfera privada, lo que conlleva a sentimientos de inseguridad al momento de introducirse al mercado laboral.

Finalmente, Olavarría (2017), analiza también los profundos cambios en las relaciones familiares producto de la precarización del trabajo que emerge tras la imposición del modelo neoliberal en Chile, planteado la pregunta de cuál es el "nuevo orden de género" que emerge de este cambio en las condiciones de trabajo. Para el autor la precarización del trabajo afecta y precariza fuertemente también las relaciones familiares y la masculinidad hegemónica.

En otro orden de cosas, los datos estadísticos respecto a la situación laboral de las mujeres en Chile confirman que, por ejemplo, la tasa de participación laboral en la población chilena por sobre los 15 años es de un 59,5\%, de los cuales un 71,3\% corresponde a los hombres y un $48 \%$ a mujeres (Encuesta Nacional de Empleo, 2017); mientras que los datos sobre las razones de la inactividad de las personas que están fuera del mercado laboral, evidencian que un $97,4 \%$ de mujeres señalan como causal "razones familiares permanentes" frente a sólo un 2,6\% de hombres (Encuesta Nacional de Empleo, 2017).

Respecto a las personas ocupadas por sexo según rama de actividad, las cifras destacan una importante tendencia a ciertas ramas masculinizadas y otras feminizadas, claramente asociadas a las labores consideradas tradicionalmente como propias de cada género. Así en la rama de "explotación de minas y canteras" encontramos que un 94,1\% de los ocupados son hombres, frente a un $8,6 \%$ de mujeres; mientras que en la rama de la "industria manufacturera" un $66,5 \%$ de los ocupados son hombres frente a un 33,5\% de mujeres; asimismo, en la rama de "construcción" se emplean un 94.3\% de hombres frente a un exiguo $5.7 \%$ de mujeres. En el otro polo encontramos que en la rama de la "enseñanza" se emplean un $70.4 \%$ de mujeres frente a un $29.6 \%$ de hombres, situación similar a la que observamos en la rama de "servicios sociales y salud" donde un $71.8 \%$ son mujeres frente a un $28.2 \%$ de hombres (Encuesta Nacional de Empleo, 2017). Los datos son concluyentes y ratifican ampliamente la discusión teórica planteada en los párrafos anteriores.

Otro aspecto de tensión en las relaciones de género producto del ingreso de la mujer al mercado laboral tiene relación con los escasos cambios producidos en el tiempo dedicado 
al trabajo doméstico. Díaz (2004), da cuenta de que, si bien las mujeres trabajadoras deben dedicar gran parte de su tiempo a la producción, deben al mismo tiempo mantener horas de dedicación a las tareas de reproducción, teniendo que resolver ellas mismas las tensiones existentes entre el trabajo productivo y reproductivo, ergo, los datos refuerzan esta afirmación. La Encuesta Nacional de Uso del Tiempo Libre en Chile (2015), concluye que "Las mujeres registran mayor participación y tiempo que los hombres a los trabajos no remunerados, sean de cuidados, doméstico para el propio hogar o quehaceres domésticos y de cuidados para otros hogares en los días de semana" (INE, 2015), agregando que el 48,9\% de las mujeres participa en el trabajo de cuidados no remunerado a integrantes del hogar, contra un $36,2 \%$ de los hombres, otro dato que ratifica los pocos cambios producidos en la división del trabajo señalan que mientras que las mujeres que participan en el trabajo doméstico para el propio hogar dedican en promedio 3,99 horas diarias, frente a las 1,91 horas que dedican los hombres.

De manera similar, la Encuesta Nacional sobre uso del tiempo (Enut, 2015), evidencia que las mujeres dedican unas 5,5 horas promedio para el ocio y la vida da social, frente a las 6,27 horas promedio que dedican los hombres. Asimismo, el Estudio de Conciliación VidaTrabajo del Ministerio de Desarrollo Social (2017) manifiesta, entre otros datos, que frente a la pregunta "¿Hay situaciones en las que usted necesitaría estar al mismo tiempo en la casa y en el trabajo?" un $28 \%$ de mujeres señaló que "siempre o casi siempre", frente a un 10\% de hombres que afirmó lo mismo. Y la opción de "A veces" fue respondida afirmativamente por un $35 \%$ de mujeres frente a un $17 \%$ de hombres, quiénes además en un $73 \%$ señalaron que nunca necesitaban estar "al mismo tiempo" en la casa y el trabajo, opción que sólo fue señala por un $37 \%$ de mujeres.

\section{Aspectos sociodemográficos de La Araucanía}

La Región de La Araucanía es una de las dieciséis regiones en que se divide Chile. Se conforma de dos provincias: Cautín y Malleco, sus capitales provinciales, respectivamente, son Temuco y Angol. La Araucanía está compuesta por 32 comunas y su capital regional es la ciudad de Temuco. Está ubicada al centro del país, limita al noroeste y norte con la región del Biobío, al este con Argentina, al sur con la Región de Los Ríos y al oeste con el océano Pacífico.

La Araucanía es la región con la mayor extensión regional en Chile y la quinta más poblada, por detrás de las regiones Metropolitana de Santiago, de Valparaíso, del Biobío y del Maule. De acuerdo a mediciones efectuadas por el Instituto Geográfico Militar (I.G.M), la región cuenta con una superficie de $31.842,3 \mathrm{Km} 2$, lo que representa el 4,2\% del territorio americano e Insular.

La población de la Región de La Araucanía, según el Censo 20173, es de 957.224 habitantes, de la cual 465.131 corresponde a personas de género masculino y 492.093 personas de género femenino, no incluyéndose un registro de personas trans o no binarias. Otro antecedente relevante corresponde a las zonas de residencia de la población, donde 678.544 personas viven en la zona urbana y 278.680 en la zona rural. De la población total,

3http://www.inearaucania.cl/archivos/files/pdf/Ediciones\%20Especiales/Compendio\%202017.pdf 
destaca que $34,3 \%$ corresponde a habitantes pertenecientes a algún pueblo originario, principalmente el mapuche, mientras que un 1,1\% son migrantes internacionales.

La Región de La Araucanía, según registro CASEN 20174, presenta un 28,5\% de la población en situación de pobreza multidimensional (correspondiente a 68.7652 personas), situándose 7,8 puntos porcentuales por sobre la media nacional $(20,7 \%)$, ocupando el nivel de pobreza más alto del país. De las personas en situación de pobreza multidimensional el 60,7\% habita en zonas rurales de La Araucanía, mientras que sólo el 39,3\% lo pertenece a zonas urbanas. En la Provincia de Cautín el 27,7\% de su población se encuentra en situación de pobreza multidimensional, lo que equivale a 202.529 personas. Mientras que para la Provincia de Malleco el 31,1\% de su población es pobre, es decir, 71.466 personas.

Por otra parte, es importante precisar que el sector comercio, dentro del cual se encuentra el retail, representa un 10,9\% de participación en el PIB regional de La Araucanía, según datos del 2014 (Observatorio Laboral Araucanía, 2018). Cabe precisar que para el año 2017 el sector comercio representó la rama de la economía donde se ubica la fuerza laboral más importante en la región, con un 19,3\%, dentro del cual las mujeres representan el 45,9\% de las personas ocupadas en esta rama frente a un 54,1\% de hombres (Encuesta Nacional de Empleo, 2017). Además, el ingreso promedio del sector comercio es de $\$ 341.054$, siendo a su vez la mediana de ingresos de \$281.648 (Encuesta Suplementaria de Ingresos, 2017, INE), de tal forma que la brecha salarial entre hombres y mujeres es de un -18,1 \% (Encuesta Suplementaria de Ingresos, 2017, INE).

\section{Diseño metodológico}

\section{Tipo de estudio}

La preferencia empírica y metodológica del estudio corresponde al enfoque cuantitativo. La investigación se desarrolló en la ciudad de Temuco, Región de La Araucanía, durante los años 2017 y 2018. Participaron 205 trabajadores del retail de cinco empresas, estas son: Easy (32\%), Líder (14\%), Cugat (20\%), Unimarc (20\%) y Paris (14\%). Con el objetivo de resguardar la paridad de sexos se elaboró una encuesta individual que fue respondida por 103 hombres y 102 mujeres $(n=205)$. A la fecha de la aplicación del cuestionario, la totalidad de las y los trabajadores que componen la muestra poseía algún tipo de contrato laboral con la empresa donde presta servicios, destacando el tipo de contrato indefinido (94\%), a plazo fijo $(5 \%)$ y por reemplazo $(1 \%)$.

El cuestionario, supervisado por profesionales de las ciencias sociales, contuvo 47 preguntas y su estructura estuvo conformada por módulos con interrogantes de puntaje, escala de Likert, dicotómicas y abiertas breve. En términos cronológicos, para efectos del estudio, se realizó una capacitación al equipo de encuestadores, se estableció contacto con informantes clave que permitieron avanzar en la aplicación del instrumento y, finalmente, se procedió a desarrollar un análisis descriptivo, correlacional y de tablas dinámicas con el programa SPSS. El periodo de aplicación del cuestionario fue gradual durante el periodo 2017-2018, debido a que la mayoría de la muestra cumple funciones asociadas a la atención

4http:/ / observatorio.ministeriodesarrollosocial.gob.cl/casenmultidimensional/casen/docs/Resultados_pobreza_Casen_2017.pdf 
de público, lo cual fue determinante para aplicar el cuestionario en tiempos de descanso o post jornada laboral.

\section{Participantes}

Las características de las personas que conformaron la muestra se fundamentaron en los siguientes criterios:

a) Que al momento de la aplicación del instrumento trabajara en alguna de las empresas del retail de La Araucanía.

b) Que tuviera vínculo contractual con la empresa con una antigüedad de al menos seis meses.

c) Que tuviese residencia en la Región de La Araucanía al momento de responder el cuestionario.

Desde el enfoque cuantitativo, se aplicó un cuestionario a una muestra aleatoria de trabajadores del retail que residen principalmente en Temuco (69\%) y Padre las Casas ${ }^{5}$ $(13 \%)$. Respecto a algunas características sociodemográficas y económicas de la muestra, cabe destacar que el rango etario es 19-69, con una media de 38 años; un 39\% se considera perteneciente al pueblo mapuche, mientras que el $61 \%$ sostiene no pertenecer a ningún pueblo originario. Respecto al salario liquido mensual, cabe señalar que la opción “Menos de $\$ 250.000$ " corresponde a un $15 \%$; la alternativa “Entre $\$ 250.001$ y $\$ 350.000$ " equivale a un $39 \%$; la preferencia “Entre $\$ 350.001$ y $\$ 451.000$ " equivale a un $29 \%$; la alternativa "Entre $\$ 451.001$ y $\$ 551.000 "$ corresponde a un $12 \%$, y, para la opción “Más de \$551.001" respondió un $4 \%$ del total.

\section{Técnica de producción de datos}

El instrumento se elaboró para ser aplicado exclusivamente a trabajadores del retail, utilizando un lenguaje propio del sector económico en cuestión. Se obtuvieron datos referentes a seis dimensiones de análisis (además de los datos sociodemográficos), a saber: Condiciones laborales; Participación política; Derechos de los trabajadores; Cambios en el mundo del trabajo; Percepción del ambiente (post)laboral, y Tiempo libre y ocio. Para los fines de la presente investigación, se enfatizará en dos de las dimensiones señaladas ${ }^{6}$, estas son: Condiciones laborales y Percepción del ambiente (post)laboral. La definición operacional de ambas es la siguiente:

-Condiciones laborales: aspectos socioeconómicos, sanitarios y políticos que permiten englobar el impacto de la práctica laboral de las y los trabajadores en tiempos y espacios vinculados a la producción de actividades que conllevan al desarrollo económico de la empresa donde presta servicios.

-Percepción del ambiente (post)laboral: actividades que conllevan a captar la sensación de las y los trabajadores del retail sobre la relevancia de sus actividades y el nivel de conformidad que tienen con el trabajo realizado. Del mismo modo, permite conocer la

\footnotetext{
5 El resto de la muestra se distribuye en porcentajes que no sobrepasan el 1,5\% entre comuna como Gorbea, Lautaro, Imperial, Pitrufquén, Carahue y Freire.

${ }^{6}$ Las otras cuatro dimensiones serán abordadas en un próximo trabajo investigativo.
} 
continuidad o discontinuidad de tareas y actividades desarrolladas post jornada laboral y en el espacio doméstico.

\section{Aspectos éticos}

Con el objetivo de resguardar la integridad de los participantes de la investigación, los procedimientos éticos adoptados por el equipo respondieron a la explicación del proyecto en diversos niveles. El primero de ello correspondió a la presentación del proyecto a los dirigentes sindicales del retail de la región, quienes oficiaron de informantes clave y permitieron el nexo con los trabajadores de base.

El segundo paso se centró en la explicación de su participación desde el resguardo de los datos proporcionados y la conservación de la integridad y el anonimato de las personas encuestadas. Los encuestadores explicaron que la información obtenida no sería utilizada en su contra; podrían retirarse de la investigación cuando estimasen pertinente, y se generó durante el periodo 2018-2019 retroalimentación de los resultados en reuniones sostenidas con los sindicatos con el objetivo de generar una devolución de información a partir de su participación en el estudio.

Finalmente, cabe destacar que no hubo retribución económica por su participación, y se explicó que al responder la encuesta colaboran directamente con valiosa información respecto al retail como sector económico relevante de la sociedad chilena, visibilizando las desigualdades de género y las estructuras sociales que delimitan roles y actividades frente al trabajo remunerado y no remunerado.

\section{Resultados}

Respecto a la presentación de resultados, cabe destacar que se mostrarán derivaciones de algunas escalas y preguntas en relación con la totalidad del instrumento aplicado. El motivo de dicha selección responde a enfatizar en la organización de un foco que denota información relevante en torno a la aparición de brechas de género respecto a las condiciones y ambiente (post)laboral de las trabajadoras y trabajadores del retail. Se seleccionaron las respuestas que presentaron mayores asimetrías respecto a la situación contractual en aspectos como permanencia en el trabajo; nivel de satisfacción por el trabajo realizado; afiliación al sistema de salud; cambios en el mundo del trabajo, y actividades realizadas post jornada laboral.

En relación con el sistema de producción post-fordista, los resultados presentados están en directa relación con las actividades realizadas según género. Mientras el género femenino realiza en mayor medida actividades vinculadas a la atención directa a público y limpieza (cajera $32 \%$, promotora $11 \%$ y aseo $27 \%$ del total), el género masculino realiza mayoritariamente actividades vinculadas a la vigilancia y fuerza física (carnicería 17\%, guardia de seguridad $12 \%$ y reponedor $14 \%$ del total). Esto se relaciona directamente con un trabajo inestable (alta rotación) y de baja retribución. Factores clave en el posicionamiento de la precarización de las y los trabajadores del retail, dan cuenta del predominio de la inestabilidad laboral, y cómo las mujeres se alzan de manera desigual en el mercado. 


\section{Condiciones laborales}

Como se mencionó anteriormente, se optó por profundizar respecto a las condiciones laborales de las y los trabajadores del retail, considerando tanto aspectos económicos y sociales como la percepción que tienen sobre diversas temáticas vinculadas al mundo del trabajo.

Con el objetivo de conocer el tiempo de permanencia en la empresa desde una perspectiva de género, la Tabla 1 evidencia las diferencias y similitudes entre el género femenino y masculino. Aunque la mayoría de las y los trabajadores no supera los cinco años trabajando en la empresa, los datos porcentuales encuentran matices desde una perspectiva de género.

Tabla 1. Tiempo de permanencia en el trabajo

\begin{tabular}{|l|r|r|}
\hline $\begin{array}{l}\text { Tiempo de permanencia en el } \\
\text { trabajo }\end{array}$ & $\begin{array}{l}\text { Porcentaje } \\
\text { Femenino }\end{array}$ & $\begin{array}{r}\text { Porcentaje } \\
\text { Masculino }\end{array}$ \\
\hline Menos de un año & $4 \%$ & $7 \%$ \\
\hline $\begin{array}{l}\text { Entre un año y un día y cinco } \\
\text { años }\end{array}$ & $21 \%$ & $22 \%$ \\
\hline $\begin{array}{l}\text { Entre cinco años y un día y } \\
\text { diez años }\end{array}$ & $16 \%$ & $18 \%$ \\
\hline $\begin{array}{l}\text { Entre diez años y un día y } \\
\text { quince años }\end{array}$ & $7 \%$ & $15 \%$ \\
\hline $\begin{array}{l}\text { Entre quince años y un día y } \\
\text { veinte años }\end{array}$ & $3 \%$ & $13 \%$ \\
\hline Más de veinte años y un día &
\end{tabular}

Fuente: elaboración propia.

Por un lado, se evidencia un predominio del género femenino respecto a un menor tiempo de permanencia en el trabajo a medida que la cantidad de años aumenta, lo cual podría responder a dos factores. El primero encuentra relación con una postergación de la inserción en el mundo laboral producto de la feminización de las labores domésticas, generando mayor tiempo destinado a tareas de reproducción del mundo privado. La segunda responde a la masculinización del espacio productivo, donde el trabajo tiende a naturalizarse para los hombres, generando mayor disponibilidad temporal para ellos respecto a lo asuntos vinculados al mundo del trabajo. Esto último, conlleva a que los hombres del retail masculinizados se disocien de las laborales reproductivas, traspasando esta carga a las mujeres.

En directa relación con lo anterior, la opinión que tienen las y los trabajadores de retail sobre su desarrollo laboral y cómo se relaciona con su quehacer, suele ser temática de alto interés para los estudios del trabajo. Para la mayoría de las y los trabajadores del retail, el trabajo que desarrollan en la actualidad tiende a ser considerado de manera positiva, permitiendo que puedan hacer lo que realmente les gusta. La Figura 1 presenta la percepción de las y los trabajadores desde el género. 
Figura 1. Hacer en su trabajo lo que realmente le gusta por género

Género femenino

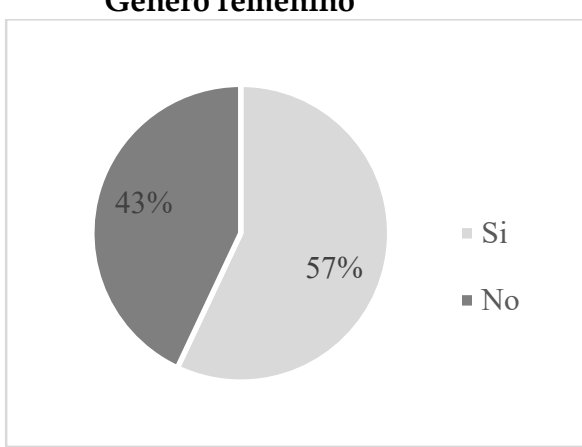

Género masculino

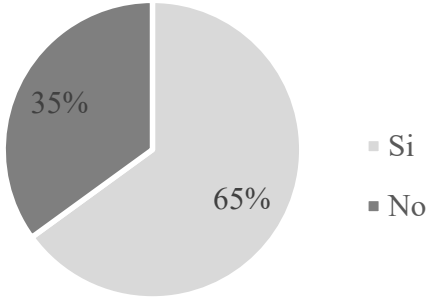

Fuente: elaboración propia.

Los resultados de la figura 1 indican que existe mayor disconformidad con el trabajo por parte del género femenino, llegando a un $43 \%$ de respuestas la opción "no". En términos específicos, de la totalidad de las y los trabajadores que respondieron con la opción "si", un $74 \%$ tienen un tiempo de permanencia en la empresa menor a los 5 años, mientras que de la totalidad de las y los trabajadores que respondieron la opción "no", un 68\% tiene un tiempo de permanencia mayor a los 5 años y 1 día. El poco tiempo de inserción en el mercado laboral tiende a generar una respuesta positiva ante la autorrealización y el gusto por el trabajo desempeñado, aspecto que se contrasta con quienes llevan más tiempo en el trabajo, desarrollando actividades sistemáticas y rutinarias (ver Tabla 2).

Por otro lado, respecto al ingreso liquido mensual que reciben las y los trabajadores del retail desde una perspectiva de género, cabe señalar que a mayor nivel de ingresos tiende a existir una preponderancia del género masculino. En este sentido, la Figura 2 evidencia que el ingreso promedio del género femenino se concentra en el rango "entre 251.001 y $\$ 350.000 "$. Asimismo, la dispersión porcentual del género femenino encuentra menor preponderancia en las opciones que concentran mayor nivel de ingresos.

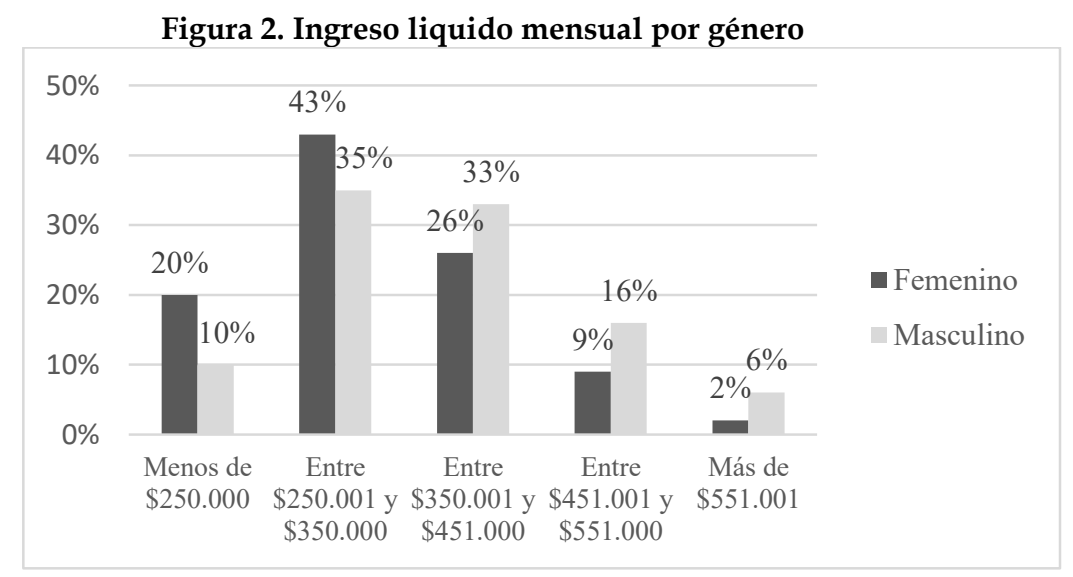

Fuente: elaboración propia.

Respecto al sistema de salud previsional en el que se encuentran afiliados las y los trabajadores del retail, por un lado, la gran mayoría está adscrita al Fondo Nacional de Salud 
(FONASA), sistema de salud chileno creado en la dictadura militar que administra y distribuye los recursos económicos desde la figura del estado. Por otro lado, emerge la opción Instituciones de Salud Previsional (ISAPRE), sistema de salud que fue creado bajo la dictadura militar y que permite que los trabajadores puedan depositar sus cotizaciones obligatorias en organismos privados. Esta opción contiene un absoluto predominio masculino de preferencias con un $11 \%$ de respuestas.

Figura 3. Sistema de salud según género

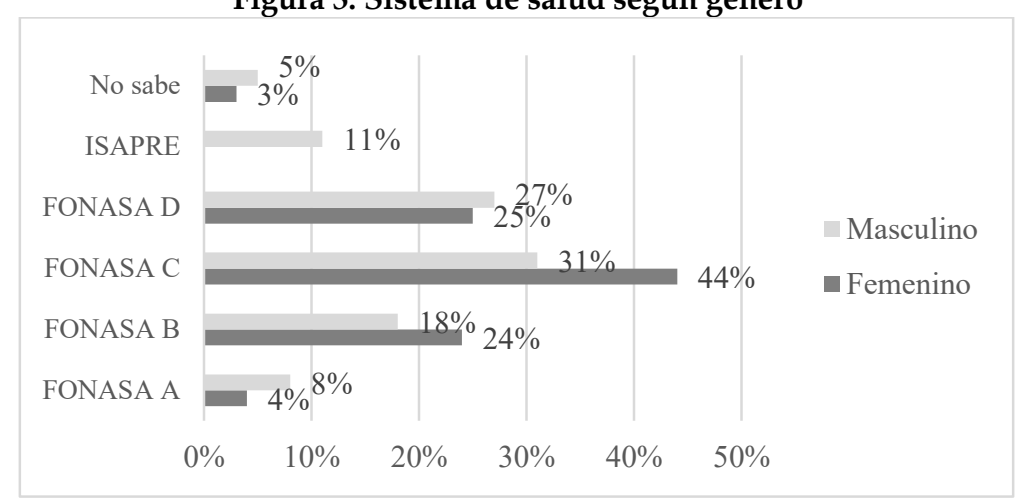

Fuente: elaboración propia.

La figura 3 presenta las diferencias de género en la afiliación al sistema de salud y su respectivo fondo, encontrando significativas oposiciones entre el sistema público (FONASA) y el sistema Privado (ISAPRE). Respecto al sistema público de salud, cabe destacar que FONASA se subdivide en cuatro tramos ${ }^{7}$, de los cuales el tramo C presenta la mayor cantidad de trabajadores y trabajadoras afiliados, con un $31 \%$ para el género masculino y un $44 \%$ para el género femenino, le sigue en cantidad de preferencias la opción tramo D con un $27 \%$ para el género masculino y un $25 \%$ para el femenino, lo cual está directamente asociado con el ingreso mensual (ver figura 2) y la cantidad de trabajadores que reciben un sueldo que oscila entre \$250.001 y \$451.001. Asimismo, resulta particularmente llamativo que en el sistema ISAPRE no figuren personas de género femenino. Las posibles causas del nulo porcentaje del género femenino en la opción ISAPRE pueden asociarse al castigo económico que propicia el sistema privado a las mujeres en edad fértil; la menor remuneración que perciben las mujeres mensualmente en comparación a los hombres, y el costo de contrato de un plan que tiende a ser mayor para aquellas mujeres de 30 años o más.

7Fonasa A: personas indigente so carentes de recursos; Fonasa B: personas que perciben un ingreso imponible menor a \$2500.000; Fonasa C: personas que perciben un ingreso imponible mayor a $\$ 250.000$ y menor o igual a $\$ 365.000$; Fonasa D: personas que perciben un ingreso imponible mayor o igual a \$365.001. 
Figura 4. Canalización de demandas laborales al interior de la empresa

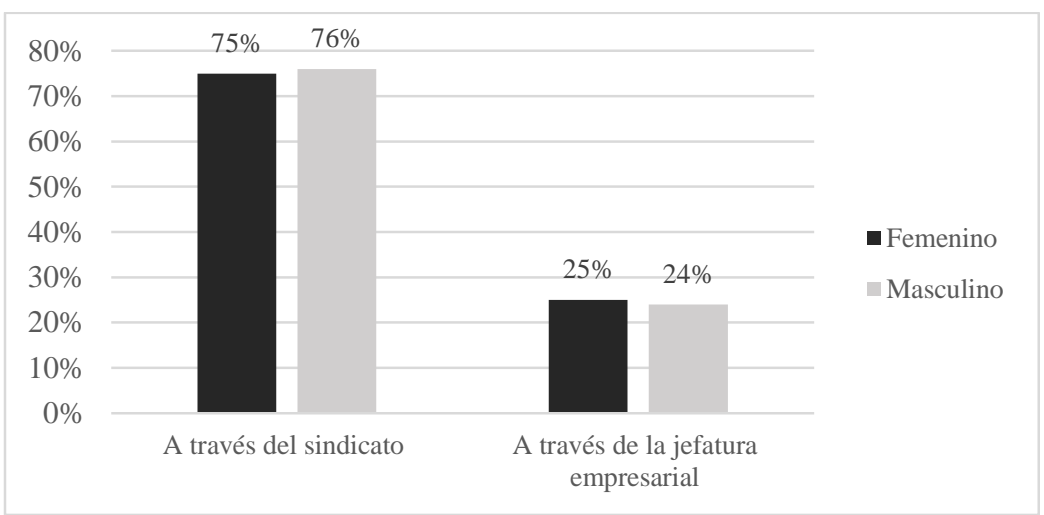

Fuente: elaboración propia.

En el contexto de la vía utilizada para canalizar las demandas políticas de las y los trabajadores del retail, la Figura 4 presenta una similitud respecto a la preferencia por el sindicato según género. Al aglutinarse las preferencias en dos sectores (Sindicato y Jefatura empresarial), el predominio del sindicato registra un $75 \%$ femenino y $76 \%$ masculino del total de la muestra, lo que está directamente relacionado con el nivel de sindicalización de los trabajadores, cifra que alcanza un 93\% del total de participantes. En este sentido, el sindicato sigue ocupando un papel fundamental en la negociación colectiva de las y los trabajadores del retail, más allá de los retrocesos y avances alcanzados.

\section{Ambiente laboral y post laboral}

Las Tablas 2 y 3 presentan información alusiva a los cambios en el mundo del trabajo, contemplando una evaluación en escala de Likert a partir de cinco enunciados. La Tabla 2 considera las respuestas del género femenino, encontrando como ejes críticos aspectos vinculados a la necesidad de trabajar en un lugar donde se valoren las capacidades de mejor manera (50\% "muy de acuerdo"), sometimiento a una fuerte carga laboral $(46,1 \%$ "muy de acuerdo") y desarrollo de trabajo en el último tiempo de manera sistemática y rutinaria (48,9\% "muy de acuerdo").

Tabla 2. Cambios en el mundo del trabajo según género femenino

\begin{tabular}{|l|l|l|l|l|l|}
\hline \multicolumn{8}{|c|}{ Muy en } \\
desacuerdo En desacuerdo Indeciso & De acuerdo & Muy de acuerdo \\
\hline $\begin{array}{l}\text { Durante el último tiempo, en } \\
\text { mi lugar de trabajo hay } \\
\text { puestos que han sido } \\
\text { reemplazados por máquinas. }\end{array}$ & & $28 \%$ & $22 \%$ & $10 \%$ & $11 \%$ \\
\hline $\begin{array}{l}\text { En mi lugar de trabajo, las } \\
\text { mujeres reciben un trato }\end{array}$ & $23 \%$ & $24 \%$ & $13 \%$ & $26 \%$ & $14 \%$ \\
\hline
\end{tabular}




\begin{tabular}{|l|l|l|l|l|l|}
\hline $\begin{array}{l}\text { económico y social igualitario } \\
\text { al de los hombres. }\end{array}$ & & & & & \\
\hline $\begin{array}{l}\text { Me gustaría trabajar en un } \\
\text { lugar donde se valoren mis } \\
\text { capacidades de mejor manera. }\end{array}$ & $4,4 \%$ & $3,3 \%$ & $10 \%$ & $32,3 \%$ & $50 \%$ \\
\hline $\begin{array}{l}\text { Siento que los trabajadores del } \\
\text { retail están sometidos a una } \\
\text { fuerte carga laboral. }\end{array}$ & $7,7 \%$ & $5,5 \%$ & $11 \%$ & $29,7 \%$ & $46,1 \%$ \\
\hline $\begin{array}{l}\text { Durante los últimos años he } \\
\text { desarrollado mi trabajo de } \\
\text { manera sistemática y rutinaria } \\
\text { a través del cumplimento de } \\
\text { las tareas que me han sido } \\
\text { asignadas. }\end{array}$ & $1,2 \%$ & $4,4 \%$ & $41,1 \%$ & $48,9 \%$ \\
\hline
\end{tabular}

Fuente: elaboración propia.

La Tabla 3 considera las respuestas del género masculino, de manera similar a la Tabla 2, los ejes críticos se relacionan con aspectos vinculados a la necesidad de trabajar en un lugar donde se valoren las capacidades de mejor manera (45,8\% "muy de acuerdo"), sometimiento a una fuerte carga laboral (57,5\% "muy de acuerdo") y desarrollo del trabajo en el último tiempo de manera sistemática y rutinaria (47,1\% "muy de acuerdo").

Tabla 3. Cambios en el mundo del trabajo según género masculino

\begin{tabular}{|l|l|l|l|l|l|}
\hline \multicolumn{5}{|c|}{ Muy en $\begin{array}{l}\text { En } \\
\text { desacuerdo } \\
\text { desacuerdo }\end{array}$} & \multicolumn{1}{c|}{ Deciso } \\
acuerdo & \multicolumn{1}{c|}{$\begin{array}{l}\text { Muy de } \\
\text { acuerdo }\end{array}$} \\
\hline $\begin{array}{l}\text { Durante el último tiempo, en mi } \\
\text { lugar de trabajo hay puestos que } \\
\text { han sido reemplazados por } \\
\text { máquinas. }\end{array}$ & $36 \%$ & $14 \%$ & $16 \%$ & $10 \%$ \\
\hline $\begin{array}{l}\text { En mi lugar de trabajo, las } \\
\text { mujeres reciben un trato } \\
\text { económico y social igualitario al } \\
\text { de los hombres. }\end{array}$ & $12 \%$ & $17 \%$ & $15 \%$ & $34 \%$ & $22 \%$ \\
\hline $\begin{array}{l}\text { Me gustaría trabajar en un lugar } \\
\text { donde se valoren mis } \\
\text { capacidades de mejor manera. }\end{array}$ & $6 \%$ & $4,8 \%$ & $8,4 \%$ & $34,9 \%$ & $45,8 \%$ \\
\hline $\begin{array}{l}\text { Siento que los trabajadores del } \\
\text { retail están sometidos a una } \\
\text { fuerte carga laboral. }\end{array}$ & $5,7 \%$ & $11,5 \%$ & $6,9 \%$ & $18,4 \%$ & $57,5 \%$ \\
\hline $\begin{array}{l}\text { Durante los últimos años he } \\
\text { desarrollado mi trabajo de } \\
\text { manera sistemática y rutinaria a } \\
\text { través del cumplimento de las }\end{array}$ & $3,5 \%$ & $14,1 \%$ & $8,2 \%$ & $27,1 \%$ & $47,1 \%$ \\
\hline
\end{tabular}




\begin{tabular}{|l|l|l|l|l|l|}
\hline $\begin{array}{l}\text { tareas que me han sido } \\
\text { asignadas. }\end{array}$ & & & & & \\
\hline
\end{tabular}

Fuente: elaboración propia.

Paradójicamente con las respuestas encontradas en la Figura 1, tanto en la Tabla 2 como en la Tabla 3 los enunciados que presentan características como insuficiente valoración del trabajo realizado, fuerte carga laboral y trabajo desarrollado de manera rutinaria, se posicionan como opciones de mayor preferencia por parte de la muestra encuestada. De igual modo, cabe destacar que el tipo de trabajo realizado se enmarca en un contexto de monotonía e invariabilidad en el trascurso del tiempo, cuestión que afecta significativamente tanto el compromiso con la empresa de trabajo como la proyección laboral a mediano plazo.

En otro ámbito, cabe destacar la gradual automatización de los puestos de trabajo, donde el $21 \%$ del total de trabajadores y trabajadoras considera que es una problemática que en la actualidad no resulta muy relevante pero que tiene una alta proyección, generando una reestructuración en las condiciones laborales del retail.

Finalmente, con el objetivo de describir lo que ocurre en el espacio reproductivo una vez que ha concluido la jornada laboral, considerando la división sexual del trabajo y las diferencias de género, la Figura 5 evidencia la preferencia por diversas funciones que puede realizar una trabajadora o un trabajador del retail al momento de llegar a su hogar.

Figura 5. Actividades que realiza en su casa luego de la jornada laboral según género

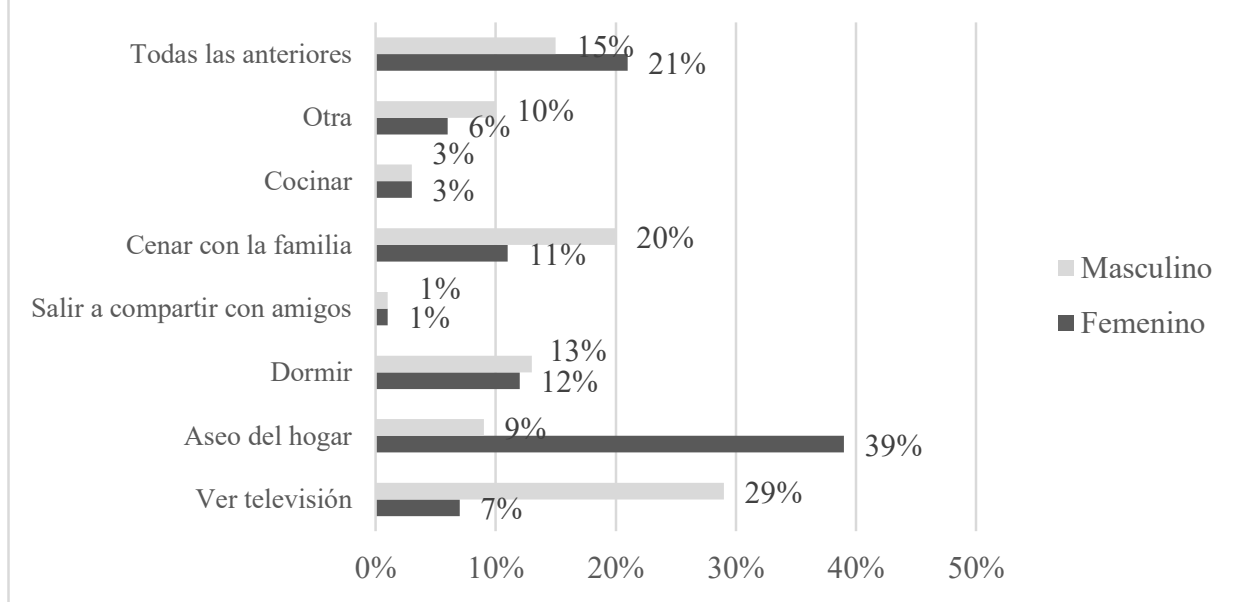

Fuente: elaboración propia.

Dentro de las preferencias y diferencias expuestas en la Figura 5, el género masculino presenta mayor interés por actividades como ver televisión (29\%), cenar con la familia (20\%), dormir $(13 \%)$, aseo del hogar (9\%), cocinar $(3 \%)$ y salir con amigos $(1 \%)$. Respecto a las preferencias del género femenino, cobra alta adscripción la alternativa labores destinadas al aseo del hogar (39\%), le sigue, dormir (12\%), cenar con la familia (11\%), ver televisión (7\%), cocinar $(3 \%)$, y, salir a compartir con amigos (1\%). En la alternativa "otras opciones" 
destacadas por ambos géneros, se encuentran actividades como uso de redes sociales y compras en grandes tiendas del mercado.

Tabla 4. Asociación entre Género y Actividad que realiza cuando llega a casa

Pruebas de chi-cuadrado

\begin{tabular}{|l|l|l|l|}
\hline & Valor & gl & $\begin{array}{l}\text { Sig. asintótica } \\
\text { (bilateral) }\end{array}$ \\
\hline $\begin{array}{l}\text { Chi-cuadrado de } \\
\text { Pearson }\end{array}$ & 33,421 & &, 000 \\
N de casos válidos & 186 & & \\
\hline
\end{tabular}

Fuente: elaboración propia.
Medidas simétricas

\begin{tabular}{|l|r|l|}
\hline & Valor & $\begin{array}{l}\text { Sig. } \\
\text { Aproxi } \\
\text { mada }\end{array}$ \\
\hline $\begin{array}{l}\text { V de } \\
\text { Cramer } \\
\begin{array}{l}\text { N de casos } \\
\text { válidos }\end{array}\end{array}$ &, 000 \\
\hline
\end{tabular}

Tabla 5. Asociación entre Género y Actividades realizadas el fin de semana Pruebas de chi-cuadrado

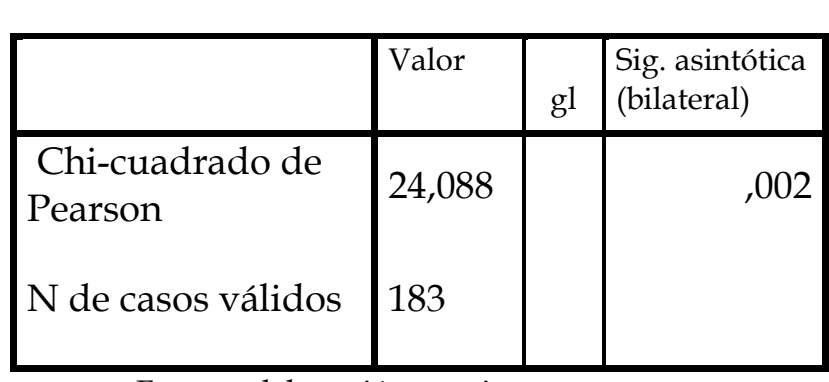

Fuente: elaboración propia.
Medias simétricas

\begin{tabular}{|l|l|l|}
\hline & Valor & $\begin{array}{l}\text { Sig. } \\
\text { aproxim } \\
\text { ada }\end{array}$ \\
\hline V de Cramer &, 363 &, 002 \\
N de casos válidos & 183 & \\
\hline
\end{tabular}

Finalmente, hemos decidido observar niveles de asociación entre variables. En este sentido, a partir del supuesto de que el género femenino se encarga mayoritariamente de las actividades reproducivas, se aprecia en la Tabla 4, según el coeficiente de chi-cuadrado, asociación entre las variables Género y Actividad que realiza cuando llega a casa post trabajo, debido a que la significación es menor 0,05. El objetivo de esta prueba fue comparar la distribución observada de los datos con una distribución esperada. Luego, se revisó Coeficiente de $\mathrm{V}$ de Cramer, coeficiente que permite ver la asociación de variables nominales, para observar la intensidad en la asociación, y se evidenció alta asociación con un valor de 0,424 de un máximo de 1 .

En una línea similar, la Tabla 5 presenta asociación entre Género y Actividades que realiza el fin de semana, según el coeficiente chi-cuadrado la significación es menor a 0,05. Se revisó $\mathrm{V}$ de Cramer y se obtuvo un valor de 0,363 , lo que indica alta asociación. Los motivos están vinculados a que la mayoría de las mujeres realizan actividades vinculadas al espacio doméstico durante el tiempo libre, mientras que la mayoría de los hombres realiza actividades en el espacio público como deportes, paseos y encuentros con amigos. 
A partir de las Tablas 4 y 5, se puede apreciar la existencia de diferencias significativas respecto a la feminización de las labores domésticas vinculadas al aseo del hogar, cuestión que conlleva a plantearse la vigencia de la división sexual del trabajo y la desigualdad de género en el ámbito reproductivo, como también el predominio del género masculino en actividades asociadas al espacio público.

\section{Conclusiones}

Como logramos observar en los resultados de la encuesta, son varios los aspectos que podemos destacar y analizar sobre la realidad de los hombres y mujeres que trabajan en el retail. En primer lugar, podemos dar cuenta de las diferencias de género que se evidencian en diversas variables tales como: 1) Acceso diferenciado al sistema de salud, donde no encontramos ninguna mujer que pertenezca al sistema privado; 2) Diferencias de género en el tiempo de permanencia en el trabajo, donde claramente las mujeres se ubican entre un año y cinco años; 3) Diferencias en las actividades que realizan hombres y mujeres al llegar a su casa, y 4) Diferencias salariales, donde manifiestamente las mujeres se ubican en los salarios más bajos, a pesar de ser un sector altamente feminizado.

Por un lado, cabe señalar que las tensiones en el ámbito de las diferencias de género y precariedad laboral están íntimamente enlazadas con la realidad socioeconómica de La Araucanía. En este sentido, la emergencia de categorías como pobreza y exclusión social posicionan a la región en los puestos de avanzada a nivel nacional, lo cual releva el sector económico aquí estudiado como un caso particular que refleja fielmente la consolidación del modelo neoliberal. Por otro lado, consideramos que esta realidad permea las relaciones sociales en diversos ámbitos de la vida cotidiana, y en ello el retail no queda al margen. Aspectos críticos como salario, salud y satisfacción con el trabajo irrumpen como variables centrales en las problemáticas de las y los trabajadores, reproduciendo desigualdades que se encarnan en aspectos de carácter sociocultural como el género y el ambiente laboral.

La información analizada en relación al nivel de sindicalización permite considerar una relación infructuosa entre las demandas por mejorar las condiciones laborales y el cumplimiento de estas, lo que conlleva a interrogar el papel actual de los sindicatos como medios de organización política que tributan a mejorar la calidad de vida de las y los trabajadores, no así su rol histórico en las luchas políticas de las y los trabajadores. Los resultados aquí presentados exhiben una correlación inversa entre canalización de demandas políticas a través del sindicato y nivel de satisfacción por las labores realizadas.

Creemos que los datos descriptivos y analíticos presentados aportan en un campo de alta vacancia relacionado con las condiciones y el ambiente laboral de trabajadoras y trabajadores del retail, los cuales han sido escasamente abordados en la región desde un enfoque como el aquí presentado. En este sentido, se abren ejes de discusión para los futuros estudios que aborden la problemática con perspectiva de género, los cuales debiesen atender a los procesos de precarización que configuran tanto la esfera productiva como reproductiva de la vida social. Destacamos algunos como: aspectos vinculados al papel de la militancia política e ideología de trabajadores precarizados; el rol que ocupa el ocio y la recreación en relación con el trabajo como eje articulador de la sociedad contemporánea, y la función de los medios de comunicación en sus vidas cotidianas. Los resultados 
presentados son críticos respecto a la predominacia de la división sexual del trabajo en el retail de La Araucanía, donde las mujeres, a la vez que se insertan en el espacio productivo, deben cumplir funciones fundamentales en la reproducción de la vida doméstica. Esto pone en evidencia la vigencia del trabajo invisible (Hatton ,2017) y el nuevo orden de género (Olavarría, 2017).

Los hallazgos presentados aportan en la discusión sobre la precarización y feminización del trabajo de las mujeres en el sector servicios en dos niveles. En primer lugar, los resultados emergen de un contexto específico que puede ser extrapolado a otras realidades del continente, siempre y cuando se resguarden las particularidades económicas y socioculturales de la región. Teniendo en consideración que las desigualdades de género se tornan representativas de la estructura social capitalista, el retail es un sector profundamente atravesado por esta problemática, y como tal, no puede disociarse de la realidad imperante. El retail encarna la esencia del sistema socioeconómico imperante donde la precariedad de sus trabajadores y trabajadoras no solo queda en el espacio laboral, más bien constituye un modo de vida reflejado en la cotidianeidad.

En segundo lugar, los resultados permiten distinguir las principales dimensiones que reproducen las desigualdades de género en diversos ámbitos de la vida cotidiana como el trabajo, la salud y el espacio doméstico, los cuales en la actualidad nacional han sido foco de reivindicaciones sociales. Estas demandas se alzan cada vez con mayor decisión por parte de los sectores oprimidos y explotados.

Sin lugar a duda, se abren más interrogantes que las respuestas aquí presentadas respecto a las y los trabajadores del retail, y que esperamos sean abordadas en el corto plazo con el objetivo de contribuir en el posicionamiento de los estudios en torno al trabajo y género en un sector formal y de relevancia para la economía chilena.

\section{Bibliografía}

Ricardo Antunes, Los sentidos del trabajo, Ensayo sobre la afirmación y la negación del trabajo, TEL-Ediciones Herramienta: Buenos Aires, 2005.

Diez tesis sobre el trabajo del presente (y el futuro del trabajo). En Trabajo, empleo, calificaciones profesionales, relaciones de trabajo e identidades laborales, Compilado por Julio César Neffa ; Enrique de la Garza Toledo ; Leticia Muñiz Terra, Buenos Aires: Consejo Latinoamericano de Ciencias Sociales, 2009.

Mariana Barattini, “El trabajo precario en la era de la globalización”, Polis, 24, 2009.

Francoise Carré \& Chris Tilly, America's biggest lowwage industry: Continuity and change in retail jobs, CSP Working Paper, 6, 2009.

Where bad hobs are better. Retail Jobs Across countries and companies, New York: Russel Sage Fundation, 2017.

Víctor Contreras, Katiuska Reynaldos,y Carolina Cardona, “Clima, ambiente y satisfacción laboral: un desafío para la enfermería", Rev Cubana Enfermería, volumen 1, N. 3, 2015.

Andrea D'Atri. Pan y rosas: pertenencia de género y antagonismo de clase en el capitalismo. Buenos Aires: Ediciones Las Armas de la Crítica, 2004. 
Ximena Díaz, "La Flexibilización de la Jornada Laboral”, en Todaro, R y Yañez, S. (Ed.), El Trabajo Se Transforma Relaciones de producción y relaciones de género, Santiago: Centro de Estudios de la Mujer, 2004.

Friedrich Engels, El origen de la familia, la propiedad privada y el Estado, en: Karl Marx y Friedrich Engels (1966), 1984.

Alda Facio y Lorena Fries, "Feminismo, género y patriarcado". Academia revista sobre enseñanza del derecho de Buenos Aires, volumen 3, N. 6, pp. 259-294, 2005.

Mariana Fernández, Julieta Longo, “Nosotros y los otros. Proceso de tercerización y respuestas sindicales en el sector petroquímico y en el comercio", Polis, Latinoamericana, Santiago, N 51, 207-235, 2018.

Silvia Federici, Revolución en punto cero. Trabajo doméstico, reproducción y luchas feministas, Madrid: Traficantes de Sueños, 2013.

Brigida García, "Los mercados de trabajo urbanos de México a principios del siglo XXI", Rev. Mex. Soc. volumen. 71, N. 1, 2009.

Rodrigo Guerra, "Persona, sexo y género. Los significados de la categoría «género» y el sistema «sexo/género» según Karol Wojtyła", Open Insight, N. 2, 139-164, 2016.

Erin Hatton, "Mechanisms of invisibility: rethinking the concept of invisible work. Work" Employment and Society, volumen 31, N. 2, pp. 336-351, 2017.

María Angélica Hernández Moreno, María Alvear Almendras, Gladys Morales Illanes y Marlela Barriga Miranda, "Social representations and perceptions on malnutrition by exceess on retail chilean workers", CiencTrab, N. 20, pp. 19-26, 2018.

Peter Ikeler, "Precarity's Prospect: Contingent Control and Union Renewal in the Retail Sector, Critical Sociology, volumen. 45, 501-516, 2018.

Dasten Julián, "Precariedad laboral en América Latina: contribuciones para un modelo para armar", Revista Colombiana de Sociología, N.40, 2017.

Daniele Kergoat, “De la relación social del sexo al sujeto sexuado”, Revista Mexicana de Sociología, N. 4, 841-861, 2003.

Philip Kotler y Gary Armstrong, "Marketing”, México: Pearson Education, 2001.

Rosa Lázaro y Olga Jubany, Interseccionalidad del género y mercado de trabajo postfordista, La Ventana volumen 5, N.46, 202-243, 2017.

Jean Lojkine, La revolución informacional, Sao Paulo: Cortez Editora, 1995.

Claudia Mazzei (Sin fecha) “La división sexual del trabajo y de la reproducción: una reflexión teórica", Herramienta. Buenos Aires.

Recuperado de:http:/ / www.herramienta.com.ar/herramienta-web-10/la-divisionsexual-deltrabajo-y-de-la-reproduccion-una-reflexion-teorica

Tomás Moulian, Chile actual: anatomía de un mito. Arcis Universidad, Santiago de Chile: LOM, 1997.

$$
\text { , El consumo me consume, Santiago:LOM, } 1998 .
$$

José Olavarría Aranguren, "Trabajo, familia y género: precarización, y sindicalización en jefes/as de hogar de familias conyugales en Chile actual", Descentrada, volumen 1, N. 2, 2017.

William Porath, Enrique Vergara, Paulina Gómez-Lorenzini y Claudia Labarca, "Cambios en la presentación de los personajes de la publicidad del retail en Chile en un contexto de modificaciones en la lógica de consumo asociadas a transformaciones socioculturales (1997-2013)", Comunicación y sociedad, N. 29, 203-225, 2017. 
Loreto Rebolledo y Ximena Valdés, "Género y orden social: dificultades para implementar relaciones de género igualitaria en la vida cotidiana". Revista Anales, N.14, 2018.

Carolina Rodríguez, "Personalidad, experiencias e imagen de marcas del retail", Ciencias económicas y administrativas, Universidad de Chile, Santiago, Chile, 2003.

Gayle Rubin, "El Tráfico de Mujeres: Notas sobre la "economía política" del sexo»". Revista Nueva Antropología, volumen 7, N. 30, 5-145, 1986.

Claudio Ramos, La transformación de la empresa chilena: una modernización desbalanceada, Santiago, Chile: Universidad Alberto Hurtado, 2009.

Andrea Sato, "División sexual del trabajo y la socialización de habilidades femeninas". El caso de las vendedoras del retail en Chile, Presentación Congreso ALAS (Asociación Latinoamericana de Sociología), Noviembre, 2018.

Joan Scott, El género: una categoría útil para el análisis histórico". En: LAMAS, Marta (Comp.). El género y la construcción de la diferencia sexual, México: Universidad Nacional Autónoma de México, Programa Universitario de Estudios de Género, 265-302, 1996.

Guy Stading, El precariado. Una nueva clase social, Barcelona: Pasado \& Presente, 2013.

Antonio Stecher, Lorena Godoy y Juan Pablo Toro, "Condiciones y experiencias de trabajo en la sala de venta de un supermercado. Explorando los procesos de flexibilización laboral en el sector del retail en Chile", Polis, Revista de la Universidad Bolivariana, Volumen 9, N. 27, 523-550, 2010.

Antonio Stecher, "Perfiles Identitarios de Trabajadores de Grandes Empresas del Retail en Santiago de Chile: Aportes Psicosociales a la Comprensión de las Identidades Laborales", Psykhe (Santiago), volumen 21 N. 2, 9-20, 2012.

Antonio Stecher y Rodolfo Martinic, "La descualificación del trabajo en tiendas por departamento" Psicoperspectivas (Valparaíso), volumen 17, N. 3, 1-12, 2018.

Cecilia Toledo, Mulheres. O gênero nos une, a classe nos divide, San Pablo: Xama, 2001.

Ximena Valdés, "Historiografía y género: hacia un balance". En Conferencias de extensión

académica (Comp.) Chile: Pasado y desafíos futuros, 2012.

Illiana Vaca, “Oportunidades y desafíos para la autonomía de las mujeres en el futuro escenario del trabajo" CEPAL, Santiago, 2019.

Sonia Yañez, "La Flexibilidad Laboral como nuevo eje de la Producción y la Reproducción”. En Todaro, R y Yañez, S. (Ed.), El Trabajo Se Transforma Relaciones de producción y relaciones de género. Santiago: Centro de Estudios de la Mujer, 2004 "Producción, Reproducción y Orden de Género", En Todaro, R y Yañez, S. (Ed.) El Trabajo Se Transforma Relaciones de producción y relaciones de género. Santiago: Centro de Estudios de la Mujer, 2004.

\section{Otras fuentes}

Estudio de Conciliación Vida-Trabajo Ministerio de Desarrollo Social Chile. Recuperado 7 de mayo de 2019 de:

http://www.crececontigo.gob.cl/wp-content/uploads/2017/12/2.EstudioConciliacio\%CC\%81n-Familia-Trabajo-06.dic_.17.pdf, 2017

Instituto Nacional de Estadística (INE) Encuesta Nacional de Empleo, 2010 - 2017. Encuesta Nacional sobre Uso del Tiempo (ENUT), 2015. Encuesta Suplementaria de Ingresos, 2017. 
Censo, 2017.

Ministerio de Desarrollo Social, Encuesta de Caracterización Socioeconómica Nacional (Casen), 2017.

Observatorio Laboral Araucanía, Informe Cuantitativo de Priorización de Sectores, Secnce, Universidad de La Frontera, Otic Sofofa.

http://observatorioaraucania.cl/wp-

content/uploads/2018/05/PR/Informe\%20Cuantitativo\%20Priorizacio\%CC\%81n\%20de \%20Sectores\%202018.pdf, 2018. 